\title{
Analytical Study on Moment-Curvature of Normal and High Strength Concrete Beams
}

\author{
B. Mayur Sharath ${ }^{1}$ and Dr. T. Muralidhara Rao ${ }^{2}$ \\ ${ }^{1}$ PG Scholar, CVR college of Engineering/Civil Engg.Department, Hyderabad, India \\ Email: mayurbannai@gmail.com \\ ${ }^{2}$ Professor, CVR college of Engineering/Civil Engg.Department, Hyderabad, India \\ Email: tmuralidhararao@gmail.com
}

\begin{abstract}
In the present study, reinforced concrete beams are considered for the calculation of minimum flexural reinforcement, Moment-Curvature relationship and ductility index using fracture energy. Normal strength concrete i.e. $\mathbf{M}_{\mathbf{2 0}}$, $\mathbf{M}_{30}, \mathbf{M}_{40}, \mathbf{M}_{50}$ and high strength concrete i.e. $\mathbf{M}_{60}, \mathbf{M}_{70}, \mathbf{M}_{80}, M_{90}$, $\mathrm{M}_{100}$ are considered in this experiment with the varying grade of steel from $\mathrm{Fe} 250, \mathrm{Fe} 415, \mathrm{Fe} 500$. In a particular grade of concrete, minimum flexural reinforcement is decreased with the increase in grade of steel. In a particular grade of steel, minimum flexural reinforcement is increased with the increase in the grade of concrete. Ductility Index is decreased with the increase in grade of concrete. Similar trend is observed when fracture energy is not considered in calculation of minimum percentage of reinforcement.
\end{abstract}

Index Terms: Fracture Energy, Minimum percentage of flexural reinforcement, Moment-Curvature, Ductility Index, Energy absorption capacity, Brittleness.

\section{INTRODUCTION}

Brittle or sudden failure occurs in concrete beams due to under reinforcement. So, a minimum percentage of longitudinal reinforcement becomes necessary. Similarly, to protect the beam from compression failure before tension failure in steel a maximum limit is set. At ultimate state sufficient rotation is observed without failure.

Rotation of the member per unit length is defined as curvature. The general consideration for flexural member is sectional ductility whereas, strain ductility depends on the material type used. The ratio of curvature at failure to the curvature at first yield is known as the curvature ductility.

\section{LiteratURE REVIEW}

G. Kaklauskas \& M. Hallgren[1] studied the deformation behaviour of high strength concrete beams analytically and experimentally. In analytical part, comparison of experimental curvatures predicted by four methods is carried out. Moment-Curvature figures are plotted and compared with the ACI code, EI code and Russian code. Better results have been obtained for a moment level of $0.4 \mathrm{M}_{\mathrm{u}}$.

Viktor Gribniak, Ieva Misiunait, Arvydas Rimkus, Aleksandr Sokolov and Antanas Šapalas[2] carried out research on residual stiffness of reinforced members. Glass fiber-reinforced polymer (GFRP) bonded to surface of concrete as reinforcement are used for the study. These specimens were simulated to study the deformation behaviour by using non-linear finite element approach.
Tejaswini V.Jadhav, Dr. V. D.Gundakalle[3] developed a moment-curvature relationship for rectangular beam and study ductility parameters under flexure. Single and double reinforced beams with varying grades of concrete and dimensions are used. With an increase in grade of concrete, moment carrying capacity is increased. Singly reinforced beams showed higher increase than doubly reinforced beams. Doubly reinforced beams showed more ductility than singly reinforced beams.

Ravi Kumar, Vimal Choudhary, K S Babu Narayan and Venkat Reddy[4] investigated the seismic risk evaluation of reinforced concrete beam and column cross section developing nonlinear axial-force and Moment-Curvature relationship. Mander's model is used in the study. Equilibrium equations, strain compatibility and constitutive relationships are used for calculating reactions and deformation.

Mohammed Fakhruddin Momin, Prashant Barbude, Kunal Bhagat, Prashant V. Muley[5] investigated the seismic risk evaluation of reinforced rectangular beam and column cross section. Modified Kent Park model is used for stress-strain relationships. A MATLAB code is written to obtain MomentCurvature relationship and compared with analytical graphs.

ZeyangSun, YangYang, WenlongYan, GangWu,[6] and Xiaoyuan He [6] conducted Moment-Curvature parametric analysis on a steel-fiber-reinforced polymer composite bar. This bar is treated as a singly reinforced rectangular concrete beam. The critical reinforcement ratio for differentiating the beam's failure mode is presented. In this study, the concept of the maximum possible peak curvature is proposed.

H. Barros, C. Ferreira, and T. Marques[7] used Mapple software to develop $(\mathrm{M}-1 / \phi)$ relationship analytically. Equilibrium equations and deformation compatibility equations are used. Ramberg and Osgood equations are represented to explain various stages of cracked concrete with steel. European code is used. Moment-Curvature relationship and load-deflection relationship is studied for reinforced concrete beams.

\section{ANALYTICAL INVESTIGATION}

A program in C-language is written to study the MomentCurvature response of reinforced concrete beam with minimum flexural reinforcement. Fracture energy of concrete is considered. 


\section{A. Material Models}

Bilinear stress-strain relationship presented in Figure. 1 is used as a material model for concrete in tension.

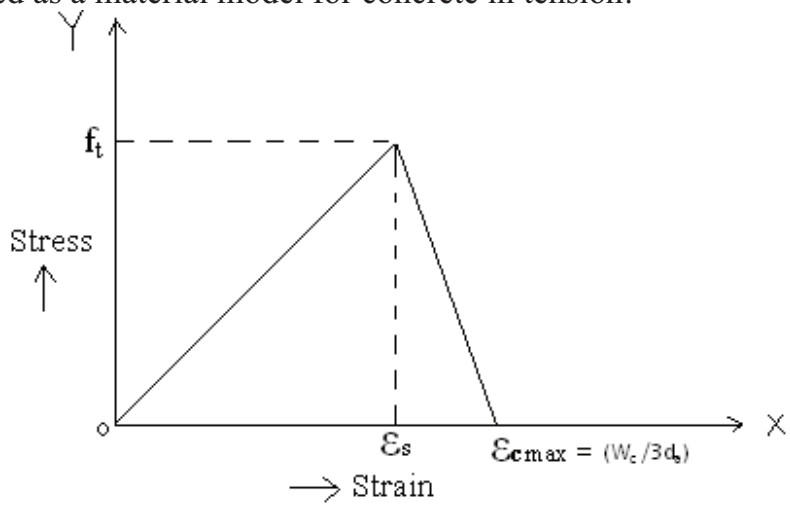

Figure 1. Material model for concrete in tension.

Second-degree parabolic model (suggested by Hognestad) is used as material model for concrete under compression.

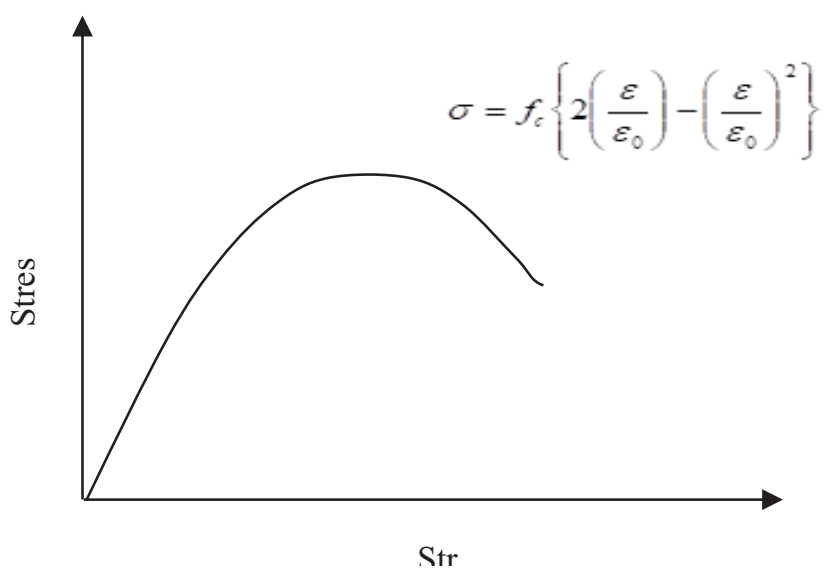

Figure 2. Material model for concrete in compression

Bilinear stress-strain relationship is used as material model for steel in tension and presented in Figure. 3.

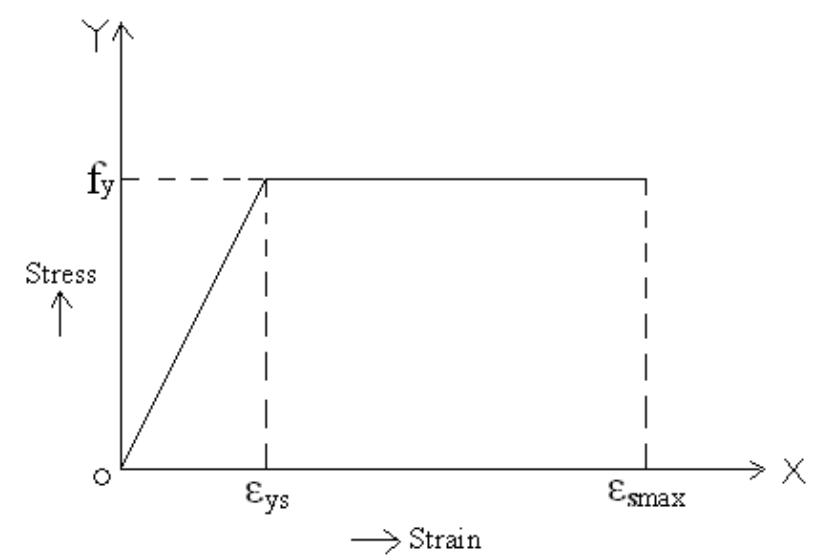

Figure 3. Material model for steel in tension

\section{B. Concrete Stess-Strain relationship}

The relationship between stress $f_{i}$ and strain eps $l_{j}$ is as follows:

(i) When epsl $<0$ (compression)

$$
\begin{aligned}
& f_{i}=-f_{c} \times \mathrm{b} \times \mathrm{st}\left[\left(\frac{-2 \times e p s l j}{0.002}\right)-\left(\frac{e p s l j}{0.002}\right)^{2}\right] \\
& \text { (ii) When } 0 \leq e p s l_{j} \leq \frac{f t}{\mathrm{Ec}}(\text { tension }- \text { pre cracking) } \\
& f_{i}=e p s l_{j} \times \mathrm{E}_{\mathrm{c}} \times \mathrm{b} \times \mathrm{st}
\end{aligned}
$$

The stress-strain relationship for the reinforcement is divided into two regions:

$$
\begin{gathered}
\text { 1. When epsl } l_{j}<\frac{f y}{E s} \\
f_{i}=\left(\frac{r o \times b \times d}{100}\right) \times \text { epsl }_{j} \times \mathrm{E}_{\mathrm{s}} \\
\text { 2. When epsl } l_{j} \geq \frac{f y}{E s}
\end{gathered}
$$

$$
f_{i}=\left(\frac{f y \times r o \times b \times d}{100}\right)
$$

C. Algorithm

1. Beam cross section is divided into number of horizontal strips of same thickness.

2. Initial Curvature value and neutral axis depth is assumed.

3. Strain at centroid of each strip is calculated for every curvature value.

4. Stress and the corresponding force in each strip are calculated as per the constitutive relationship.

5. Equilibrium condition is checked by calculating total tensile force and compressive force.

6. Moment of force in each strip about neutral axis of the beam is calculated and the algebraic sum of moments is calculated for the given curvature value.

7. Then the curvature value is increased and steps $2-6$ are repeated.

8. The variation of moment and curvature of the member is plotted.

\section{RESUlTS AND Disscussions}

The Moment-Curvature relationships for different grades of concrete and steel are presented in, Figure 4, Figure 5. Figure 6. Figure 7, Figure 8and Figure 9 respectively. 


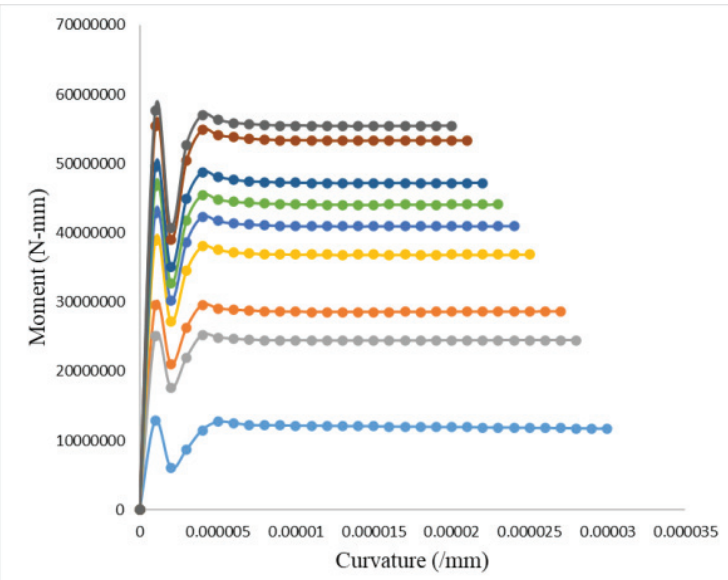

Figure 4. Moment-Curvature relationship for different grades of concrete with Fe250 steel (without Fracture Energy).

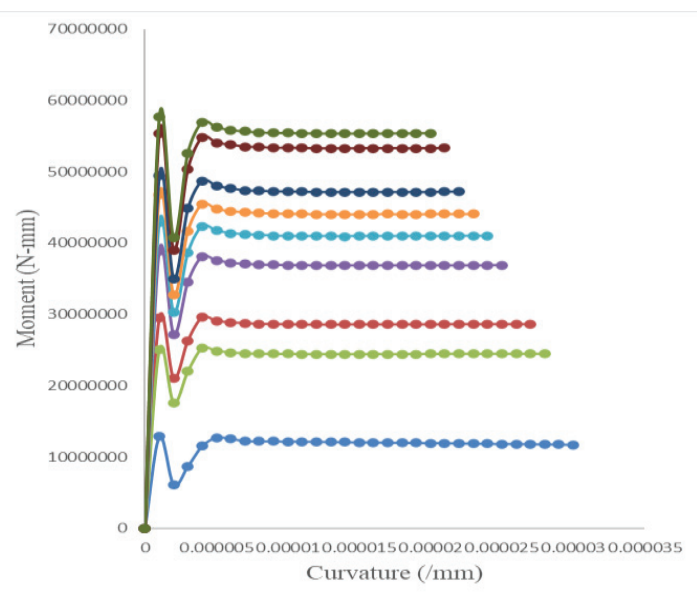

Figure 5. Moment-Curvature relationship for different grades of concrete with Fe250 steel (with Fracture Energy).

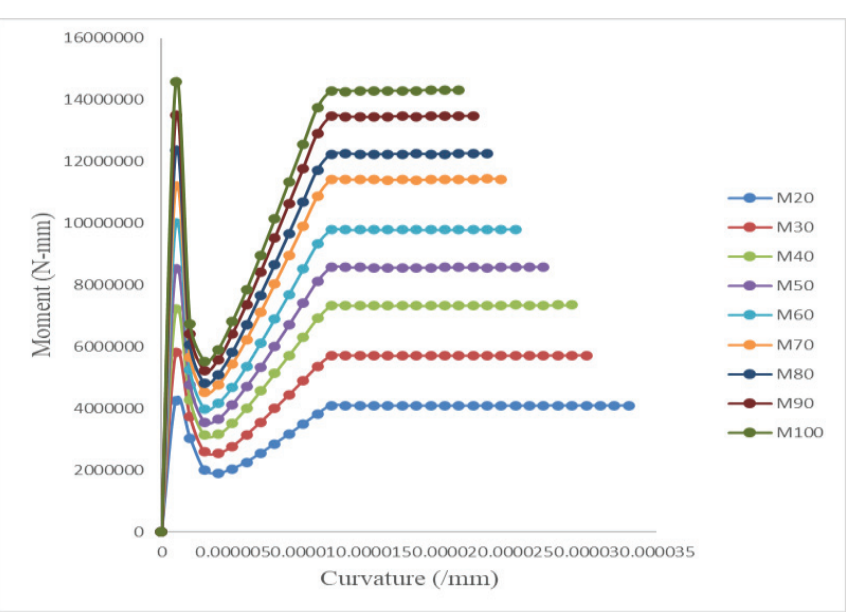

Figure 6. Moment-Curvature relationship different grades of concrete with Fe415 steel (without Fracture Energy).

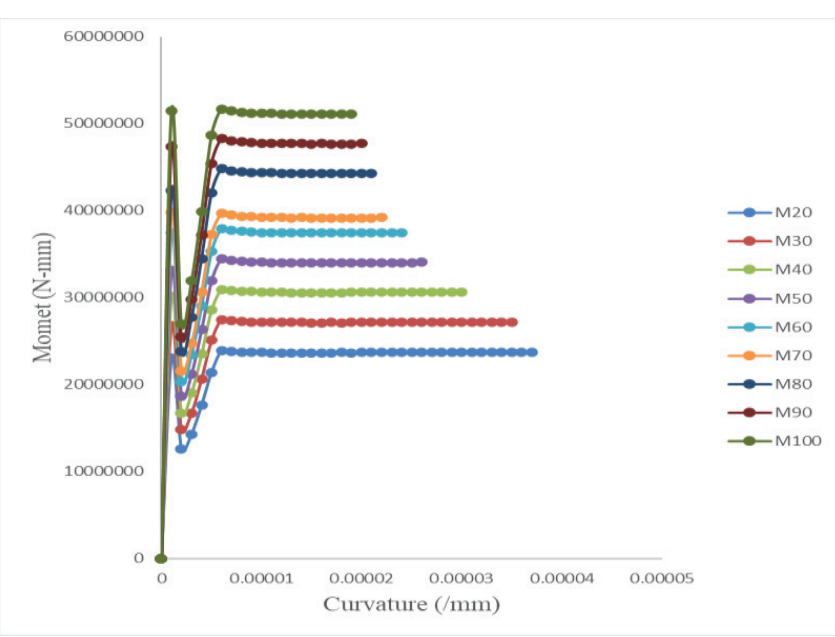

Figure 7. Moment-Curvature relationship different grades of concrete with Fe415 steel (with Fracture Energy)

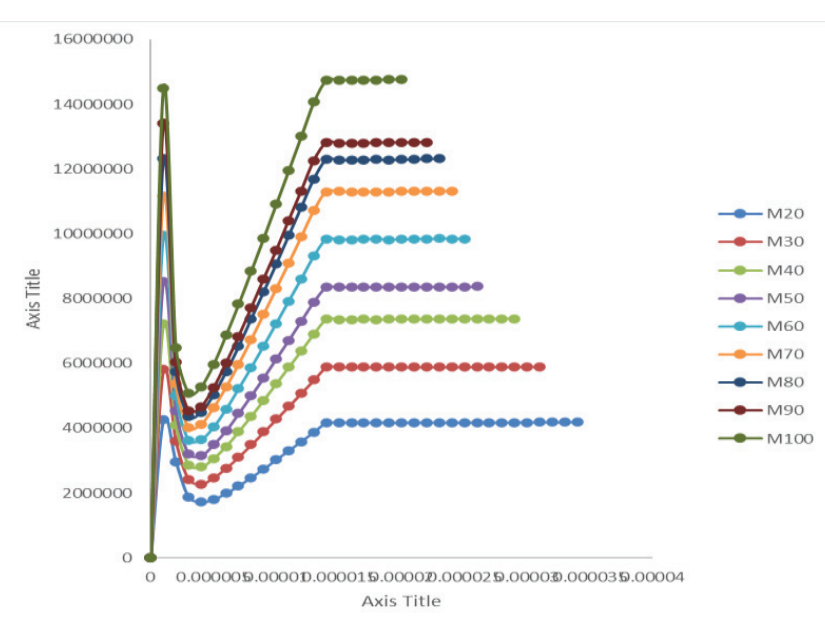

Figure 8. Moment-Curvature relationship for different grades of concrete with Fe500 steel (without Fracture Energy).

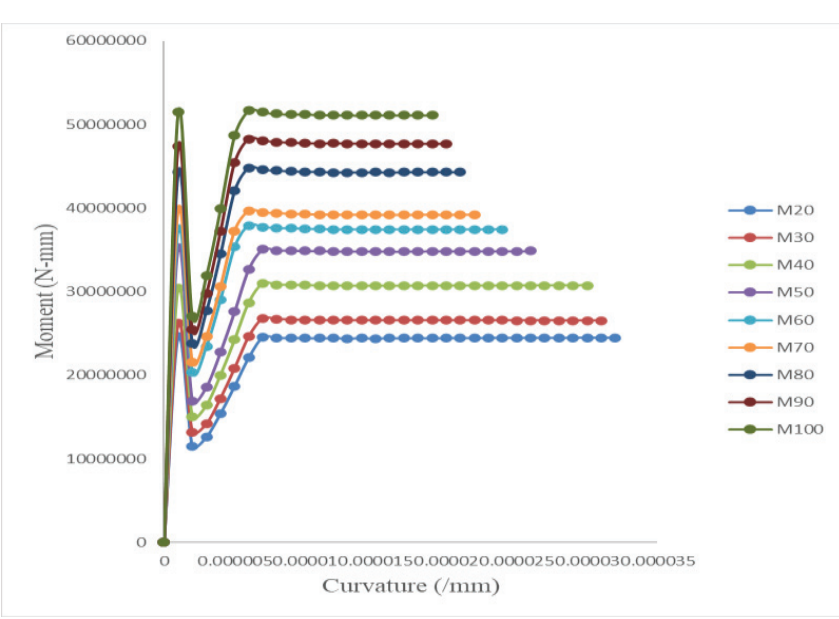

Figure 9. Moment-Curvature relationship different grades of concrete with Fe500 steel (with Fracture Energy).

The fracture energy of concrete is calculated and considered in the calculation of minimum flexural 
reinforcement. In a particular grade of concrete, minimum flexural reinforcement is decreased with the increase in grade of steel. The variation is presented in Figure. 10 and Figure 11 .

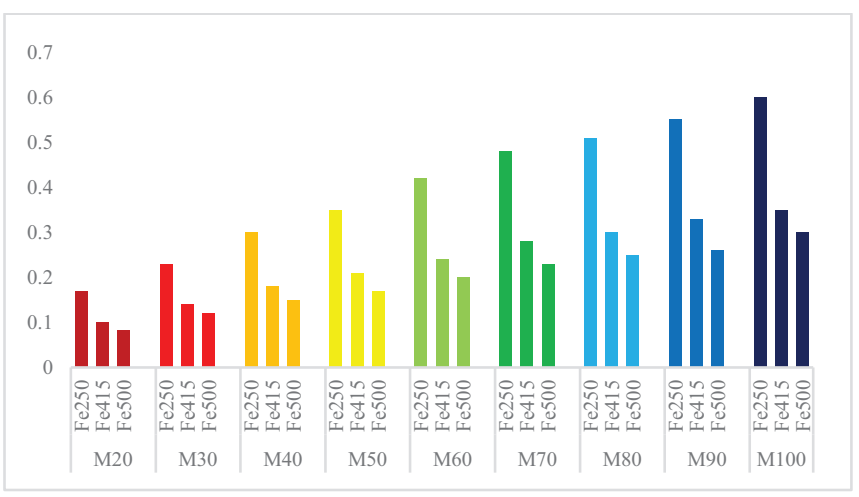

Figure 10. Minimum flexural reinforcement for different grades of concrete and different grades of steel without fracture energy.

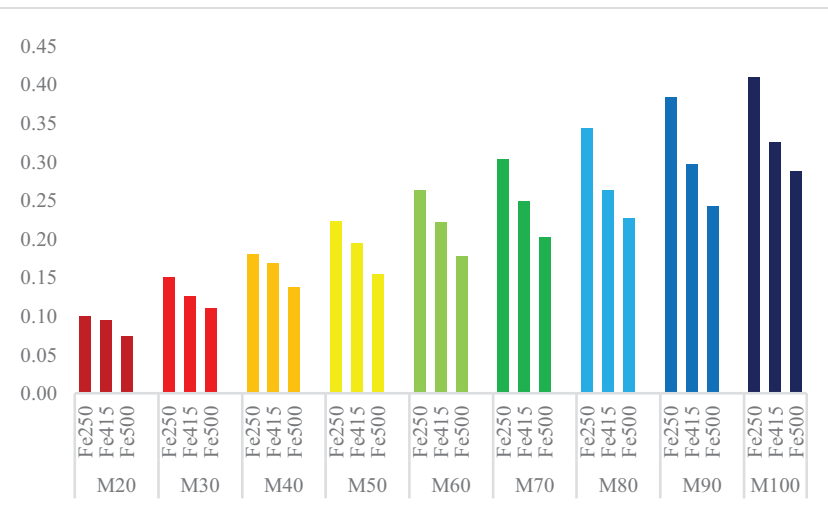

Figure 11. Minimum flexural reinforcement for different grades of concrete and different grades of steel with fracture energy.

For a particular grade of concrete, the moment at first crack, moment at first yield and the moment at ultimate shows an increase in value. The variation is presented in Figure. 12, Figure 13, Figure. 14, Figure 15, Figure 16 and Figure 17.

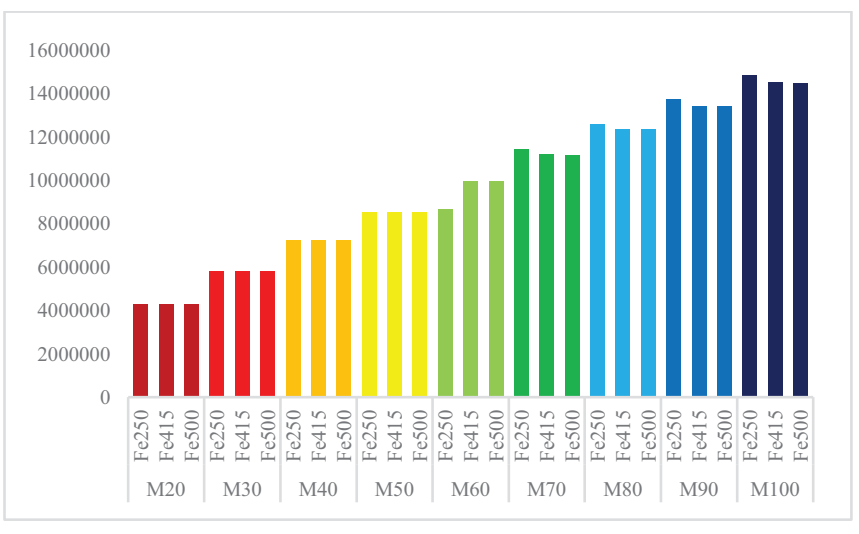

Figure 12. Moment at first crack for different grades of steel and different grades of concrete without fracture energy.

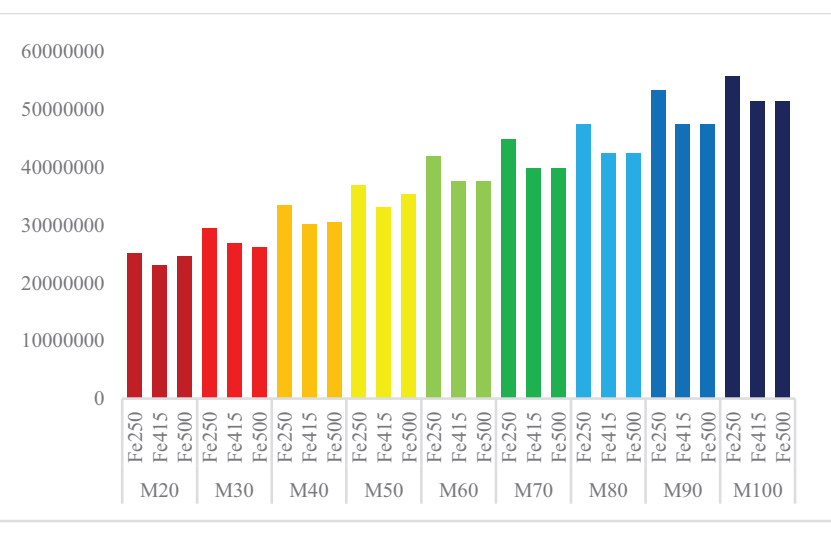

Figure 13. Moment at first crack for different grades of steel and different grades of concrete with fracture energy.

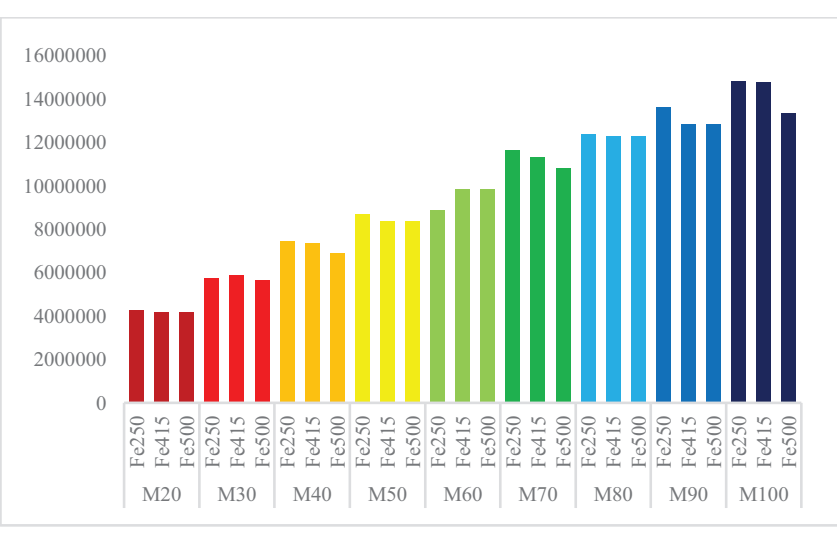

Figure 14. Moment at first yield for different grades of steel and different grades of concrete without fracture energy.

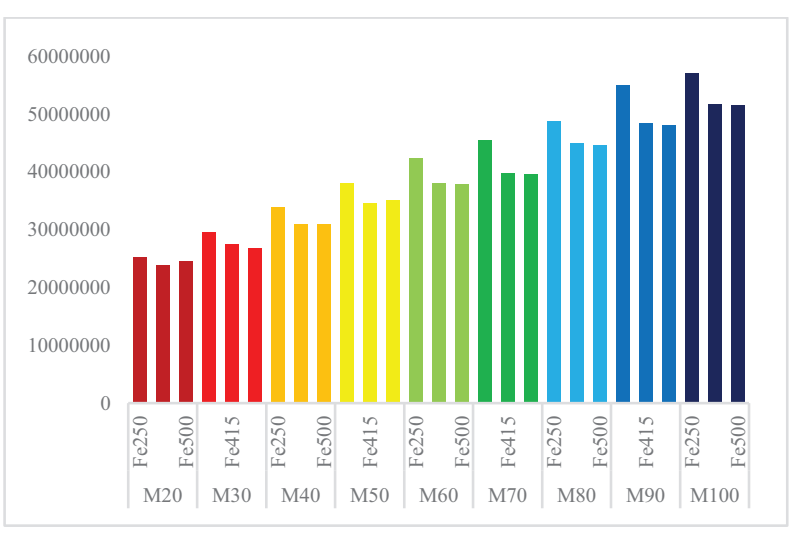

Figure 15. Moment at first yield for different grades of steel and different grades of concrete with fracture energy. 


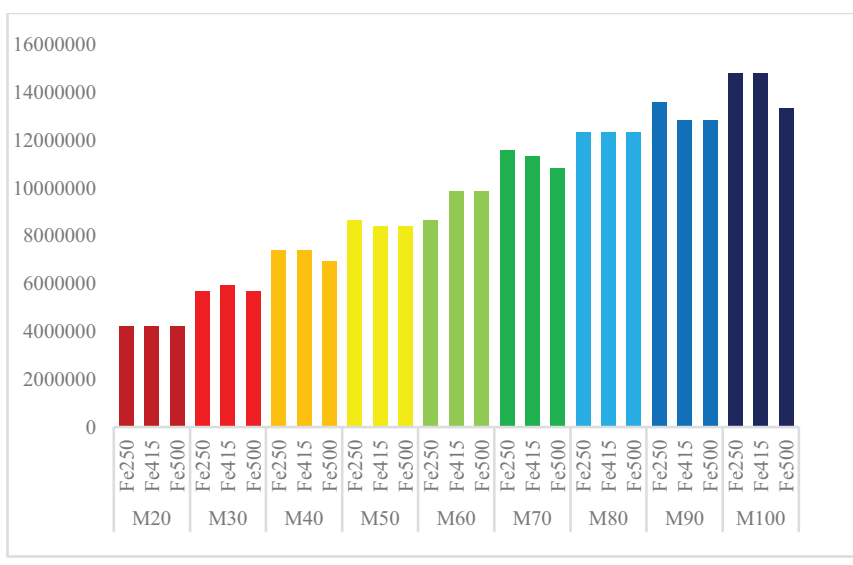

Figure 16. Moment at ultimate for different grades of steel and different grades of concrete without fracture energy.

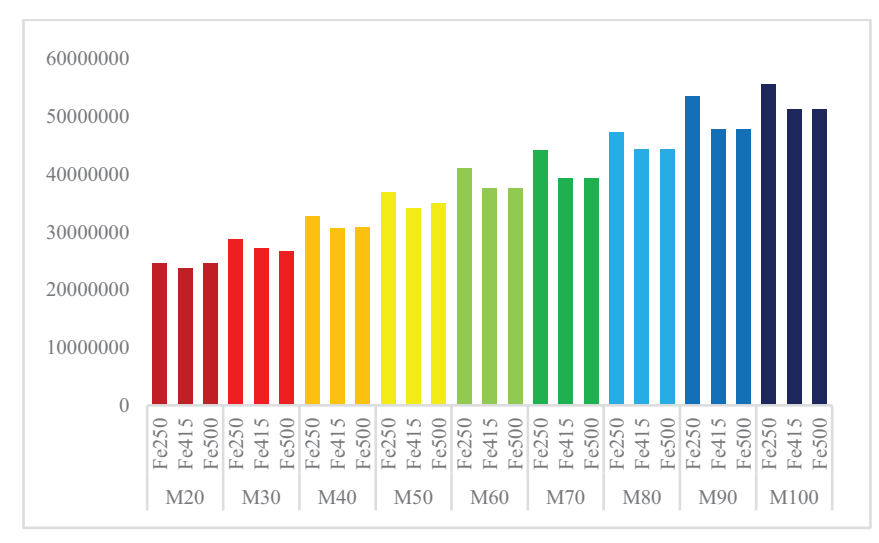

Figure 17. Moment at ultimate for different grades of steel and different grades of concrete without fracture energy.

The curvature at first yield and curvature at ultimate decrease for a particular grade of concrete with increasing grade of steel as presented in Figure. 18, Figure. 19, Figure. 20 and Figure. 21.

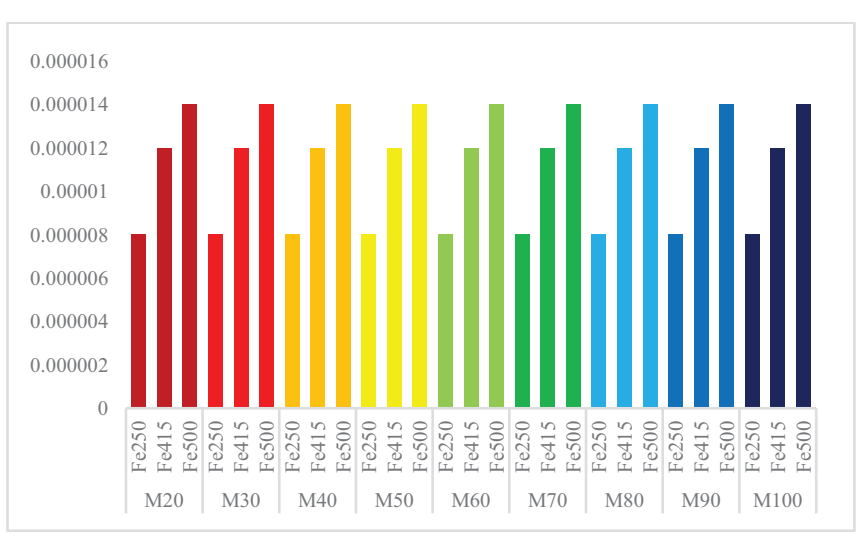

Figure 18. Curvature at first yield for different grades of concrete and different grades of steel without fracture energy.

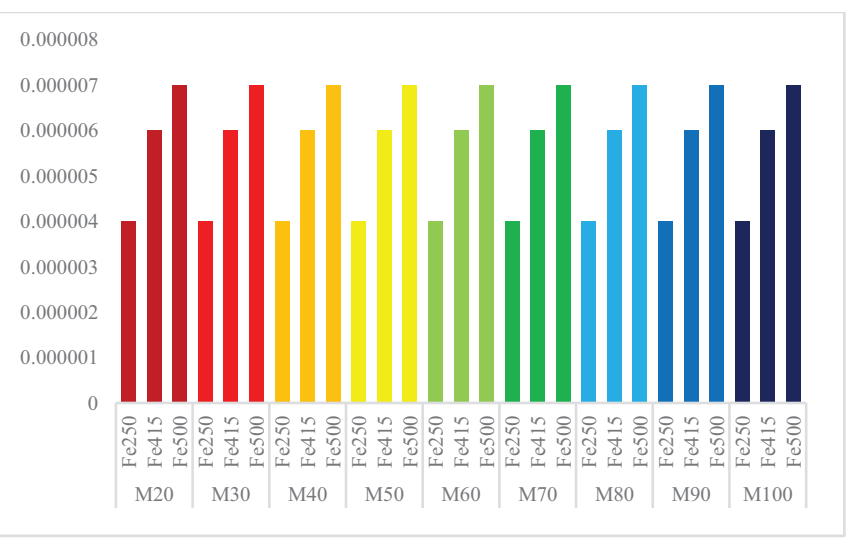

Figure 19. Curvature at first yield for different grades of concrete and different grades of steel with fracture energy.

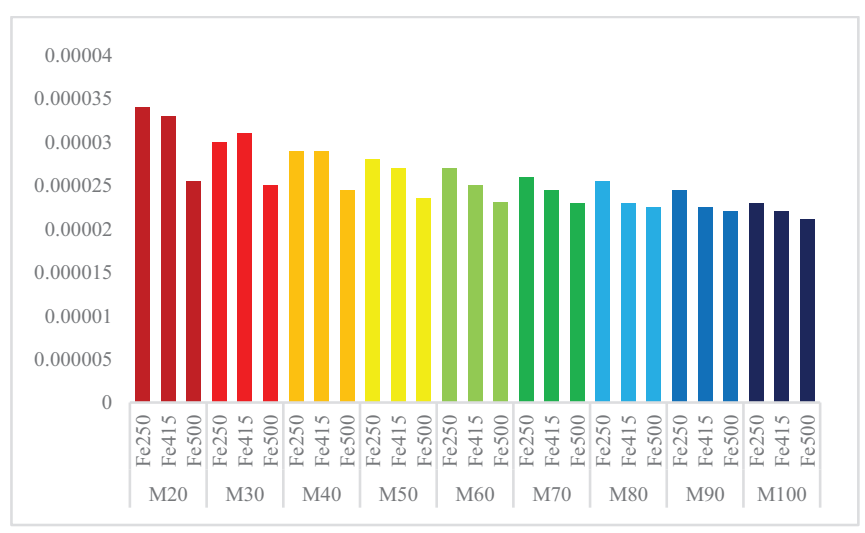

Figure 20. Curvature at ultimate for different grades of steel and different grades of concrete without fracture energy.

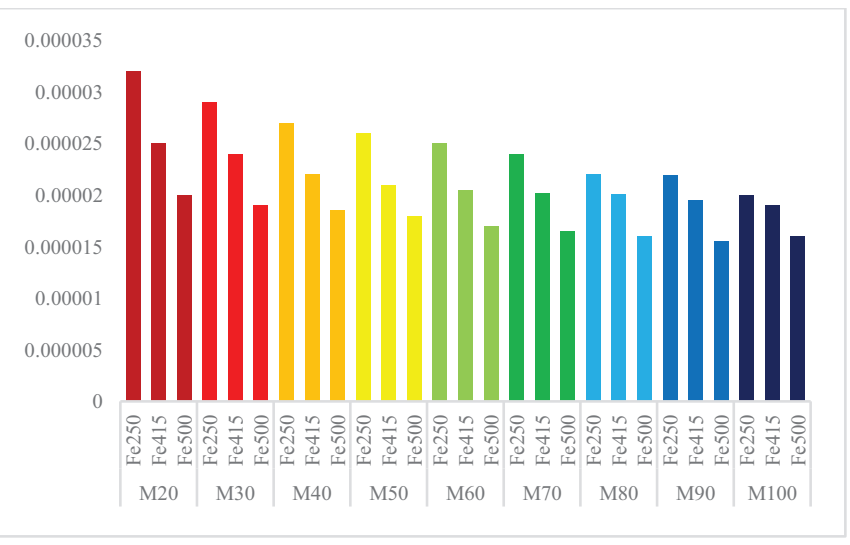

Figure 21. Curvature at ultimate for different grades of steel and different grades of concrete with fracture energy.

Ductility Index is decreased in a particular grade of concrete with the increase in grade of steel as presented in Figure. 22 and Figure. 23. 


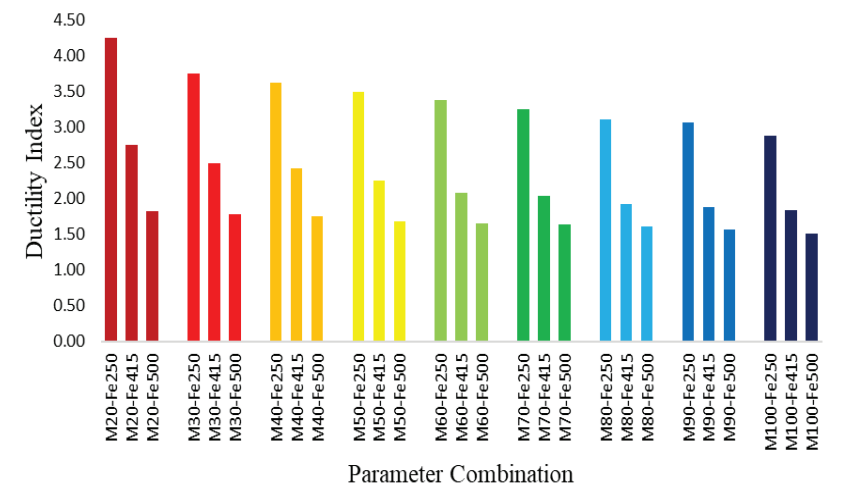

Figure 22. Ductility Index for a particular grade of concrete with varying grade of steel without fracture energy.

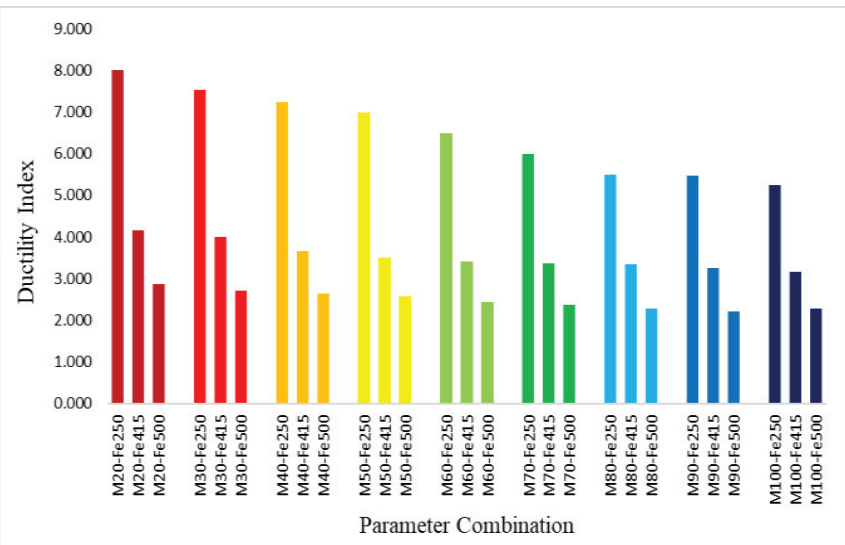

Figure 23. Ductility Index for a particular grade of concrete with varying grade of steel with fracture energy.

\section{CONCLUSIONS}

A programme in C-language was developed to find Moment-Curvature relationships, minimum flexural reinforcement and ductility properties of beams considering Fracture energy.

1. In a particular grade of steel, the moment at first yield increased with increase in grade of concrete. This may be due to increased strength and stiffness of the member with increase in grade of concrete.

2. It is found that, in a particular grade of concrete, the minimum flexural reinforcement decreased with the increase in grade of steel. This may be due to the increase in yield strength of steel with increase in grade of steel.

3. In a particular grade of steel, ductility index decreased with the increase in grade of concrete. This may be due to the increase in brittleness of concrete with the increase in the grade of concrete.

4. Higher the ductility index, higher the energy absorption capacity and vice versa.

Therefore, the fracture energy of concrete need to be calculated accurately and should be considered in the calculation of minimum flexural reinforcement.

\section{REFERENCES}

[1] G. Kaklauskas \& M. Hallgren, "Curvature Analysis of High Strength Concrete Beams", ISSN: 1392-1525, pp 357$363,2012$.

[2] Viktor Gribniak, Ieva Misiunait, Arvydas Rimkus, Aleksandr Sokolov and Antanas Šapalas, "Deformations of FRP-Concrete Composite Beam: Experiment and Numerical Analysis", Appl. Sci, pp 2, 2019.

[3] Tejaswini V. Jadhav, V. D. Gundakalle, "Effect of Medium to High Grade of Concrete and Depth on Moment Curvature Relationship for Reinforced Concrete Beams Section", IJSRD, Vol. 3, Issue 06, 2015.

[4] Ravi Kumar, Vimal Choudhary, K. S. Babu Narayan and D. Venkat Reddy, "Moment Curvature Characteristics for Structural Elements of RC Building", June 22, 2014.

[5] Mohammed Fakhruddin Momin, Prashant Barbude, Kunal Bhagat, Prashant V. Muley, "Moment Curvature Relationship for Structural Elements of RC Building Using Matlab", ISSN (Online): 2347 - 2812, Volume-5, Issue 2, 2017.

[6] Zeyang Sun, Yang Yang, Wenlong Yan, Gang Wu, and Xiaoyuan He, "Moment-Curvature Behaviours of Concrete Beams Singly Reinforced by Steel-FRP Composite Bars", 2017.

[7] H. Barros, C. Ferreira, and T. Marques, "Moment-Curvature Diagrams for Evaluation of Second Order Effects In RC Elements", ECCOMAS Congress, 2016.

[8] Daskshina Mirthy, Sudheer Reddy, "Moment-Curvature Characteristics of Ordinary Grade Fly Ash Concrete Beams", International journal of civil and structural engineering, 2010.

[9] Ravi Kumar et al, "Moment- Curvature characteristics for structural elements of $R C$ buildings", Journal on Todays Idea-Tomorrow's Technology, vol 2, June 2014.

[10] Hyo- gyong, Kwak, Sun-Pil Kim, "Non-linear analysis of $R C$ beams based on Moment-Curvature Relation", Computers and structures, 2002.

[11] M. Srikanth et al, "Moment-curvature of RC beams using various confinement models and experimental validation", Asian Journal of Civil Engineering, 2007.

[12] D. H. Travis, G. Giongo, P. Paultre, "Behaviour of Reinforced Concrete Beams Reinforced with GFRP Beam" Ibracon Structures and Material Journal, 2008.

[13] Mohd Al Amin, Md Abur, "Effect of Material Properties on Ductility of Reinforced Concrete Beams", The Institute of Malaysia, 2006.

[14] Abdel Hamid Charif, Saleh Dghaither, "Ductility of Reinforced Lightweight Concrete Beams Singly Reinforced by Steel FRP Composite Bars", Advanced Civil Engineering, 2017.

[15] Gurey Arslan, Ercan Cihanli, "Curvature-Ductility Prediction of High-Strength Concrete Beams Sections", Journals of Civil Engineering and Management,2010.

[16] Young Jang, Hoon Gyu- Park, Siu Foo Kim, "On Ductility of High Strength Concrete Beams", International Journal of Concrete Structures and Materials, 2008.

[17] Japan society of Civil Engineers (JSCE), "Standard Specification for Concrete Structure: No 15" Cl. 13.4.2, 2007. 
SYMBOLS

Depth of neutral axis

$\varepsilon \mathrm{c}_{\text {epsl }} \quad$ Strain in Concrete fiber

Es Strain in Steel

$\phi_{\mathrm{u}} \quad$ curvature at failure for beam under loading

$\phi_{\mathrm{c}} \quad$ curvature at first yield for beam under loading

$\mu \quad$ flexural ductility or curvature ductility

Es Modulus of elasticity of steel

Ec Modulus of elasticity of concrete $\mathrm{f}_{\mathrm{ck}}$

$f_{y}$

St

Ro

b

d

1
Characteristic compressive strength of concrete

Yield strength of steel

Stress in $\mathrm{i}^{\text {th }}$ strip of the beam section

Minimum percentage of reinforcement steel

Breath of the beam

Width of the beam

Length of the beam 